\title{
An Immunocytochemical Procedure for Protein Localization in Various Nematode Life Stages Combined with Plant Tissues Using Methylacrylate-Embedded Specimens
}

\author{
Paulo Vieira, Mohamed Youssef Banora, Philippe Castagnone-Sereno, \\ Marie-Noëlle Rosso, Gilbert Engler, and Janice de Almeida Engler
}

\begin{abstract}
Institut National de la Recherche Agronomique, UMR 1355 ISA; Centre National de la Recherche Scientifique, UMR 7254 ISA; Université de Nice-Sophia Antipolis, UMR ISA; 400 Route des Chappes, Sophia-Antipolis, France.

Current address of P. Vieira: Nemalab/ICAAM, Universidade de Évora, 7002-554 Évora, Portugal.

Current address M. Youssef Banora: Department of Plant Pathology, Faculty of Agriculture, Ain Shams University, Hadayek Shoubra, Cairo, Egypt.

Accepted for publication 7 June 2012.
\end{abstract}

\begin{abstract}
Vieira, P., Youssef Banora, M., Castagnone-Sereno, P., Rosso, M.-N., Engler, G., and de Almeida Engler, J. 2012. An immunocytochemical procedure for protein localization in various nematode life stages combined with plant tissues using methylacrylate-embedded specimens. Phytopathology 102:990-996.

Plant-parasitic nematodes possess a large number of proteins that are secreted in planta, allowing them to be successful parasites of plants. The majority of these proteins are synthesized mainly in the nematode subventral and dorsal glands as well as in other organs. To improve the immunovisualization of these proteins, we adapted a methacrylate embedding method for the localization of proteins inside nematode tissues,

and extracellularly when secreted in planta or within plant cells. An important advantage is that the method is applicable for all nematode stages: preparasitic as well as parasitic stages, including large mature females. Herein, the method has been successfully applied for the localization of four nematode secreted proteins, such as Mi-MAP-1, Mi-CBM2-bearing proteins, Mi-PEL3, and Mi-6D4. In addition, we could also localize 14-3-3 proteins, as well as two cytoskeletal proteins, by double-immunolabeling on preparasitic juveniles. Superior preservation of nematode and plant morphology, allowed more accurate protein localization as compared with other methods. Besides excellent epitope preservation, dissolution of methacrylate from tissue sections unmasks target proteins and thereby drastically increases antibody access.
\end{abstract}

Plant-parasitic nematodes display different parasitism strategies enabling them to develop and interact with a broad spectrum of plant hosts. Among such adaptations, the secretion of nematode proteins capable of modifying or manipulating the host environment seems to be a key element for the success of these plant pathogens. It is believed that nematode secretions synthesized in esophageal glands (two subventral and one dorsal), and other organs (e.g., amphids), have multiple physiological functions including parasitism and the induction of pathological effects in plants (reviewed by 8,30). Several techniques have been applied to address the specific nematode tissue expression of different gene candidates involved in plant-nematode interaction. This validation has been mainly achieved by performing whole-mount in situ hybridizations $(3,12,18,27)$, or whole-mount immunolocalizations, using mono- or polyclonal antibodies against nematode transcripts or proteins $(6,7,26,33,35)$, respectively, within different nematode developmental stages.

The success of the butyl-methyl methacrylate resin, first used to localize microtubules in isolated mitotic apparatus from sea urchin eggs (16), can be attributed to the fact that the plastic after polymerization can be dissolved, allowing a better antibody pene-

Corresponding author: J. de Almeida Engler

E-mail address: janice.almeida-engler@ sophia.inra.fr

* The $\boldsymbol{e}$-Xtra logo stands for "electronic extra" and indicates that the online version contains six supplementary figures. Figures 1 to 6 appear in color online.

http://dx.doi.org/10.1094/PHYTO-02-12-0031-R

(c) 2012 The American Phytopathological Society tration and epitope accessibility, therefore increasing detection sensitivity $(9,15)$. As a result, to achieve better tissue morphology and resolution, several alternative methodologies, making use of plastic polymers suitable for the localization of a wide variety of antigens in plants and animal tissues, have been established $(2,14$, 23,32,36). Another advantage is that the butyl-methyl methacrylate embedding method can be used for in situ hybridization (11), various staining methods, and morphological analysis due to the good quality of tissue preservation $(10,23,36,38)$. Other methods based on methacrylate media such as LR White and LR Gold resins have been applied for immunolocalization of proteins in nematode or infected plant roots and electronic microscopy analyses $(25,28,34)$. However, for thick sections these media present significant limitations for epitope detection, as they cannot be dissolved after polymerization, as feasible for butyl-methyl methacrylate resin.

Previously, we successfully employed a butyl-methyl methacrylate methodology to assess the detection of plant proteins $(1,9)$ and root-knot nematode (RKN), Meloidogyne incognita, secreted proteins in infected Lycopersicon esculentum (tomato) and Arabidopsis thaliana roots $(22,37)$. These studies revealed protein localization in their time frame within feeding sites during the plant-nematode interaction. Herein, we adapted a fixation method for preparasitic and parasitic stages of RKN and applied the butyl-methyl methacrylate method for the localization of one or more endogenous nematode proteins simultaneously, eventually secreted by the nematode in planta. A detailed protocol is presented that can be directly applied for simultaneous nematode and plant protein localization in various tissues during different life cycle stages of nematode infection. 


\section{MATERIALS AND METHODS}

Nematode fixation. $M$. incognita was cultured on tomato plants (L. esculentum 'St. Pierre') in the greenhouse. Freshly hatched preparasitic juveniles (J2) were obtained from mature egg masses hatched in water at room temperature. Juveniles were placed in $2 \mathrm{ml}$ Eppendorfs, centrifuged for $5 \mathrm{~min}$ at 3,000 rpm (maximum, to avoid nematode bursting) and immediately resuspended in freshly prepared fixative (4\% formaldehyde in $50 \mathrm{mM}$ Pipes buffer, $\mathrm{pH}$ 6.9), refreshed twice, and kept at $4^{\circ} \mathrm{C}$ for 7 days. To obtain isolated RKN sedentary stages, infested roots were incubated for $16 \mathrm{~h}$ at $4^{\circ} \mathrm{C}$ in a cell-wall-degrading enzyme mix: Pectinex (15\%) (Rwalco, Louvain-la-neuve, Belgium) and Celluclast (30\%) (Realco, Louvain-la-neuve, Belgium). Infested roots were then ground and RKN parasitic stages were extracted by sucrose gradient centrifugations (5). A mixed pool of sedentary nematode stages (containing $\mathrm{J} 2, \mathrm{~J} 3 / \mathrm{J} 4$, females and males) was collected by hand and fixed in $2 \mathrm{ml}$ of freshly prepared $4 \%$ formaldehyde in $50 \mathrm{mM}$ Pipes buffer, $\mathrm{pH} 6.9$, for 1 week at $4^{\circ} \mathrm{C}$. The samples were placed in a rotator at $4^{\circ} \mathrm{C}$ to allow proper fixative infiltration. Note: stock of formaldehyde is prepared from paraformaldehyde (Sigma-Aldrich) in $50 \mathrm{mM}$ Pipes buffer, $\mathrm{pH}$ 9.0, and heated at $60^{\circ} \mathrm{C}$ to dissolve. The $\mathrm{pH}$ is then adjusted to 6.9 with $\mathrm{H}_{2} \mathrm{SO}_{4}$. The $8 \%$ stock fixative is then aliquoted in $50 \mathrm{ml}$ Falcon tubes and frozen for long periods at $-20^{\circ} \mathrm{C}$. When defrosted it must look transparent before use.

Nematode dehydration. For nematode dehydration and embedding in methacrylate, the protocol was essentially performed as described by de Almeida et al. (9). Adjustments were added to the protocol. For example, dehydration steps were extended to $3 \mathrm{~h}$ (instead of $1 \mathrm{~h}$ for plant tissues) in each ethanol dilution (15\%, $30 \%, 50 \%$, vol/vol), rotating or shaking mildly at $4^{\circ} \mathrm{C}$. For each ethanol change, preparasitic juveniles were centrifuged for $5 \mathrm{~min}$ at 3,000 rpm. Nematode samples were incubated overnight at $4{ }^{\circ} \mathrm{C}$ in $70 \%$ ethanol. Samples were then further dehydrated in $85 \%$ ethanol and three times in $100 \%$ ethanol on ice for $3 \mathrm{~h}$ each. When needed, the dehydration protocol was interrupted at $70 \%$ ethanol. Samples stored in $100 \%$ ethanol became brittle and broke easily. For nematode parasitic stages, fixation and dehydration was performed in cell strainers (BD Falcon, BD Biosciences), using six-well tissue culture plates (Nunc, Dutscher) and placed on ice under mild shaking. Centrifugation of sedentary parasitic nematodes was avoided due to the risk of bursting. Fixation, dehydration, and embedding of plant tissues containing nematodes were also performed in cell strainers within six-well tissue culture plates.

Nematode embedding in methacrylate. After dehydration, ethanol was replaced by an equal volume of fresh ethanol with a butyl-methyl methacrylate mixture $(4: 1$, containing $0.1 \mathrm{mM}$ DDT, hereafter called $\mathrm{BM}$ mix), at $4{ }^{\circ} \mathrm{C}$ overnight. The following day, the solution was replaced by $100 \% \mathrm{BM}$ mix and kept overnight at $4^{\circ} \mathrm{C}$. The BM mix was refreshed and kept for 1 week at $4^{\circ} \mathrm{C}$ (samples can stay in this solution for up to 1 month or longer if needed). Subsequently, the BM mix was replaced by BM embedding medium containing $0.5 \%$ benzoin ethyl ether and $0.1 \mathrm{mM}$ DDT (BM/BEE) and incubated overnight (or longer) at $4^{\circ} \mathrm{C}$. Ultimately, samples were placed in plastic capsules (BEEM, Electron Microscopy Science) containing fresh BM/BEE and polymerized at $4^{\circ} \mathrm{C}$ for $5 \mathrm{~h}$ under UV light. Longer polymerization times may cause the sample to become too brittle. After polymerization, samples can be kept at room temperature for an indeterminate time. Note: for in situ hybridizations, polymerized samples should be stored as such, and only sectioned when needed to avoid mRNA degradation.

Sectioning methacrylate-embedded nematode. Polymerized samples were removed from the capsule and sectioned to $5 \mu \mathrm{m}$ (thicker may cause loss of sections from slides). Sections were then floated in drops of sterile water on polylysine-coated glass slides, dried on a hot plate at $60^{\circ} \mathrm{C}$, and incubated overnight at $42^{\circ} \mathrm{C}$ so that sections would adhere to the slides. Slides containing biological material were then kept in dry slide boxes at room temperature until used for immunolocalization. Note: infected root material slides must be screened under a binocular or a light microscope to select intact longitudinal sections of juvenile nematodes migrating within the roots, and to select isolated parasitic nematodes with intact heads. Sections containing the nematode head that are close to giant cells should be favored for immunocytochemical analysis. Slides containing sections of isolated nematodes can be used directly. For each case, we recommend making paired slides so that one slide containing similar sections can be used for control experiments.

Immunocytochemical analysis of nematode proteins. Slides were treated for $30 \mathrm{~min}$ with $100 \%$ acetone to remove embedding medium and to improve antibody access to the protein of interest by immunolocalization in infected roots. Sections were checked under the microscope to monitor if embedding medium was well dissolved and then dipped in $100 \%$ ethanol, rehydrated progressively in ethanol series $(85,70,50,30$, and $15 \%)$, and finally placed in $50 \mathrm{mM}$ Pipes buffer (pH 6.9). On each slide, $\approx 200 \mu \mathrm{l}$ of blocking solution (1\% bovine serum albumin in $50 \mathrm{mM}$ PIPES, $\mathrm{pH}$ 6.9) was added and covered with a coverslip and incubated for $30 \mathrm{~min}$ (or longer) at room temperature in a humid box. Primary (AB1) and secondary (AB2) antibodies were diluted 50- to 100fold and 300-fold, respectively, in blocking solution (BS) containing $0.2 \%$ DMSO. Antibodies were incubated in $\mathrm{BS}$ at $37^{\circ} \mathrm{C}$ for 30 min and centrifuged for $5 \mathrm{~min}$ at 13,000 rpm. This step removed nonspecific BSA binding antibody as centrifugation precipitate. The coverslip was then carefully removed from incubated slides and BS was then replaced by $\approx 150 \mu \mathrm{l}$ of AB1a only or mixed with $\mathrm{AB} 1 \mathrm{~b}$, or with the pre-immune-serum (PIS) of each antibody as a control. A control slide that was incubated only with the secondary antibody can also be included to check eventual background given by AB2. Note: when performing double immunolocalization, where both primary antibodies are polyclonal or monoclonal, the procedure is repeated twice; each time with one primary followed by the second antibody with different fluorochromes. This is so each antibody emits fluorescence at different wave lengths and washes are reduced to $15 \mathrm{~min}$, each time, to avoid signal loss.

Slides were placed in a humid box and incubated overnight at $4^{\circ} \mathrm{C}$. The box containing the slides was then placed at $37^{\circ} \mathrm{C}$ (optimal temperature for $\mathrm{AB} /$ antigene interaction) for $90 \mathrm{~min}$. It is advisable to ensure that slides do not dry, adding some more AB1 solution if needed. Subsequently, the coverslips were gently removed and slides were placed in racks and washed for $30 \mathrm{~min}$ in $50 \mathrm{mM}$ Pipes buffer, $\mathrm{pH}$ 6.9, with gentle agitation. Buffer was then removed and replaced immediately with ca. $150 \mu \mathrm{l}$ of AB2, cover slipped, and incubated for $3 \mathrm{~h}$ at room temperature or for $1 \mathrm{~h}$ at $37^{\circ} \mathrm{C}$. This step can also be performed overnight at $4^{\circ} \mathrm{C}$. A set of slides was incubated only with $\mathrm{AB} 2$ as a control for nonspecific binding of the secondary antibody. The slides were then washed again for $30 \mathrm{~min}$ with Pipes buffer, protected from the light to avoid fading of fluorochromes. Nuclei were then stained with 4',6-diamidino-2-phenylindole (DAPI, $1 \mu \mathrm{g} / \mathrm{ml}$ in water or $\mathrm{PBS}$ ) for $5 \mathrm{~min}$ at room temperature and rinsed briefly in deionized water to remove salts. Finally, slides were mounted in $90 \%$ glycerol for a first observation. If results were satisfactory, slides were mounted with ProLong antifade medium (ProLong antifade kit; Invitrogen Molecular Probes) since the last step is irreversible. Otherwise, additional washes with Pipes buffer can be performed before final mounting. Slides were then observed with a microscope (Axioplan 2; Zeiss) equipped for epifluorescence and differential interference contrast optics. For fluorescence observations, a double band pass filter (Zeiss filter set 23) was used to reliably separate deep-green signal from yellow-green tissue autofluorescence. Representative cytological images of 
preparasitic and sedentary stages for each protein were analyzed using a digital camera (AxioCam; Zeiss). Images of immunolabeled sections, differential interference contrast transmission, and DAPI-stained DNA (nuclei) were overlaid using the public domain Image J software. Slides can be kept for up to 2 months in dark boxes for later observation.

Antibodies. Sera directed against Mi-MAP-1 (33), Mi-CBM2bearing proteins, Mi-PEL3 (37), and Mi-6D4 (7) were used separately as primary antibodies. A polyclonal antiserum, against the mouse 14-3-3 zeta (ab52875), was obtained from ABCAM (Paris, France). For microtubule localization anti- $\alpha$-tubulin clone DM 1A (Sigma-Aldrich, St. Louis, MO) or anti- $\gamma$-tubulin serum, kindly provided by J. L. Evrardt (29), was used. The following secondary antibodies were used: Alexa-594 goat anti-mouse IgG (red), Alexa-488 goat anti-mouse IgG (green), and Alexa-488 antirabbit IgG (green), depending upon the animal used to generate the primary antibody (Molecular Probes, Eugene, OR).

Whole-mount immunolocalization and electron microscopy of preparasitic J2s. Preparasitic freshly hatched J2s were fixed in phosphate buffered saline (PBS) containing 2\% paraformaldehyde for $18 \mathrm{~h}$ at $4^{\circ} \mathrm{C}$ and $4 \mathrm{~h}$ at room temperature. Immunolocalizations on $M$. incognita preparasitic J2s were performed essentially as described by Semblat et al. (33). Primary antibody (anti-MiMAP-1) was diluted 1:50 in PBS buffer (containing $1 \mathrm{mg} / \mathrm{ml}$ of horse serum-phenylmethylsulfonyl fluoride), and secondary antibody (Alexa-488 anti-rabbit) was diluted 1:200 in PBST buffer (PBS containing $0.1 \%$ Tween 20 and $0.1 \%$ bovine serum albu-
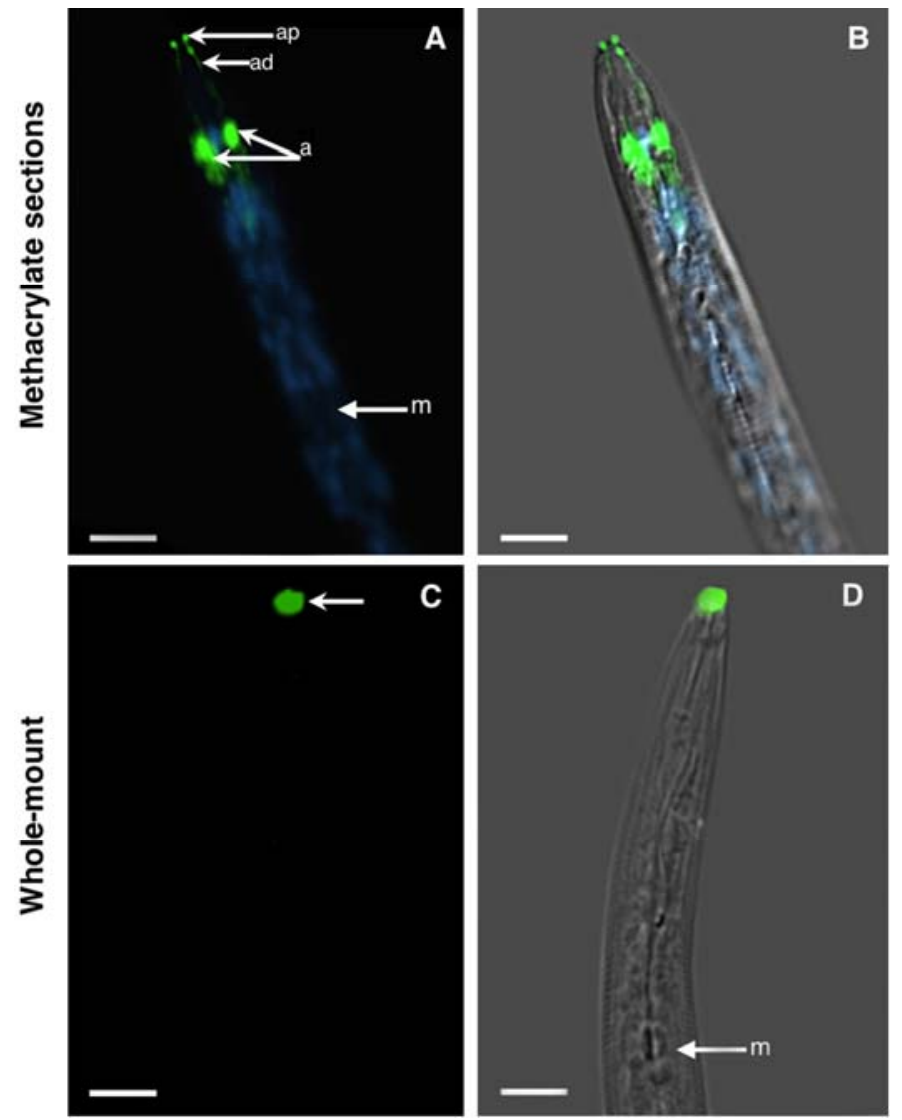

Fig. 1. Immunolocalization of the Mi-MAP-1 protein in preparasitic juveniles of Meloidogyne incognita. A and B, Images represent longitudinal sections of a butyl-methyl methacrylate mixture embedded preparasitic juveniles. MiMAP-1 was localized in the amphids (a), along the amphidial duct (ad), and the amphidial pore (ap). $\mathbf{C}$ and $\mathbf{D}$, Localization of Mi-MAP-1 in preparasitic juveniles using the whole-mount immunolocalization procedure. Mi-MAP-1 is mainly at the nematode head at locations corresponding to the amphidial pores. A and C, Fluorescence images of ALEXA-488 and DAPI-stained nuclei appear paired with corresponding DIC overlays (B and D) on the right panel. $\mathrm{m}$, metacorpus. Bars $=10 \mu \mathrm{m}$. min). Antibody-treated sections were transferred to polylysinecoated slides and observed with a microscope equipped for epifluorescence microscopy and differential interference contrast optics (Axioplan 2, Zeiss). Images were captured using an AxioCamHRc digital camera (Zeiss). Control samples were incubated with pre-immune serum in the absence of primary antibody.

Immunoelectron microscopy. Ultrastructural immunocytochemistry was performed as described in Banora et al. (1). Freshly hatched J2s were fixed in $4 \%$ paraformaldehyde, dehydrated, and embedded in acrylic resin (LR-White) before sectioning and immunogold labeling. For control, sections were processed according to the same procedure except that the primary antibody was omitted (data not shown).

\section{RESULTS AND DISCUSSION}

Often, whole-mount immunolocalization and in situ hybridization methodologies are applied for the specific localization of nematode gene transcripts or proteins from nematode tissues $(3,26)$. Although useful, both techniques require preparation of fresh biological material for each independent experiment, and protein or transcript localization is limited by the recalcitrant antibody or probe penetration in whole-mounts. Alternatively, sections of butyl-methyl methacrylate embedded material gives the possibility, with a single nematode extraction, of collecting enough material that after processing can be kept for numerous independent experiments. Each embedded capsule containing the biological material will allow the generation of a large number of subsequent nematode sections, permitting a detailed analysis of protein localization. In addition, the possibility of having a set of slides containing consecutive sections will permit the comparison of localization of different proteins in sections of the same nematode individuals. Another advantage is that capsules or slides containing samples can be stored for a long period, until the immunolocalization assay is performed. Eventually sections from the same set can also be used for in situ transcripts localization. The method can be applied on animals, as well as in plant tissues. The protocol presented here in great detail was recently validated, and successfully applied for the localization of secreted proteins in giant cells (20) illustrating the versatility of the method proposed.

Nematode tissue embedding, sectioning, and antibodies used for immunolocalization. To obtain optimal resolution, combined with efficient protein detection, nematodes must be carefully fixed. Preparasitic as well as sedentary nematodes need longer fixations than, for example, Arabidopsis tissues. In addition, to avoid damaging nematodes, gentle centrifugations were carried out for preparasitic juveniles, while the use of sieves, for the parasitic stages, was applied. Samples of all nematode stages must be fixed extensively to allow fixative penetration into the intact nematode body ( $\approx 7$ days). Whole-mount immunolocalizations and in situ hybridizations of late $\mathrm{J} 2, \mathrm{~J} 3 / \mathrm{J} 4$ and females present technical difficulties due to their increasing body size. At later developmental stages, RKN may burst during sample preparation; therefore, adapted fixation and careful handling until embedding in methacrylate is essential.

Previously, cryosectioning had been applied for protein localization in nematode or plant tissues, but tissue morphology and resolution were far from optimal (6). In addition, secondary fluorescent antibodies often give high background in most tissues when using cryosections. Similar inconveniences are also observed when using paraffin-embedded nematodes or infected plant tissues, even when showing a slightly improved morphology. The methacrylate resin, used here, attained the finest morphology, cellular structure preservation of giant cells (e.g., microtubules), and visualization of detailed organ and tissue structures in isolated nematodes as well as within nematodes inside plant tissues (Supplementary Figure 1; 22,37). 
For immunolocalization procedures we have used primary antibodies directed against Mi-MAP-1 (33), Mi-CBM2-bearing proteins, Mi-PEL3 (37), Mi-6D4 (7), and 14-3-3 (ab52875, ABCAM; Supplementary Figure 2) proteins in pre-parasitic J2 juveniles and parasitic sedentary stages. Proteins were detected using the secondary antibody anti-rabbit or anti-mouse Alexa488 , respectively. During double immunolocalizations anti- $\gamma$ tubulin polyclonal antiserum of Arabidopsis (29) was detected with the anti-rabbit Alexa-488 and the anti- $\alpha$-tubulin clone DM $1 \mathrm{~A}$ was detected with anti-goat Alexa-594.

Immunolocalization of nematode proteins in preparasitic J2. To validate our protocol, seven antibodies were used for
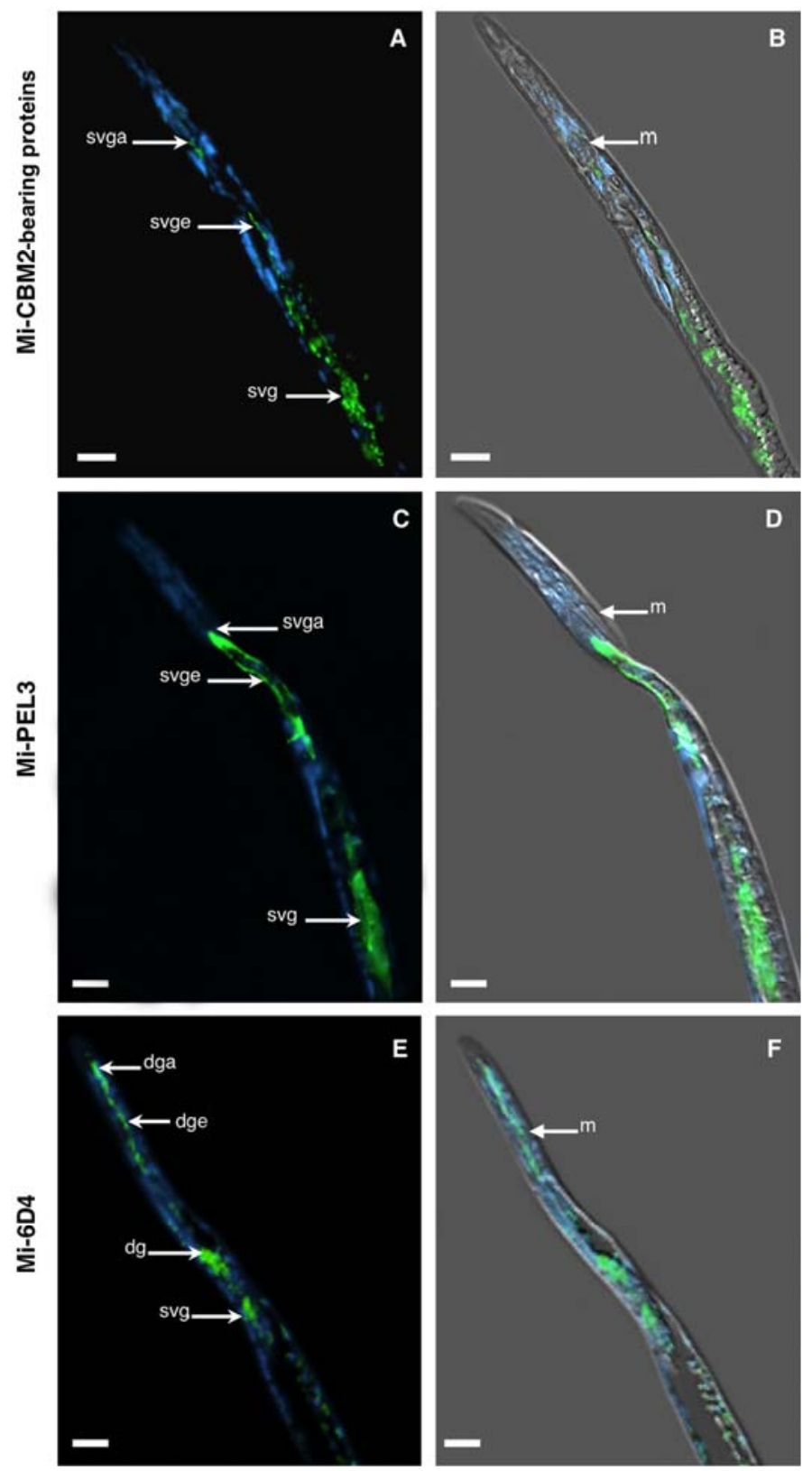

Fig. 2. Immunolocalization of nematode proteins in methacrylate sections of preparasitic juveniles of Meloidogyne incognita. A and B, Localization of Mi-CBM2-bearing proteins in the subventral glands (svg), subventral gland extensions (svge), and subventral gland ampullae (svga). C and D, Localization of Mi-PEL3 protein in the subventral glands (svg), subventral gland extensions (svge), and subventral gland ampullae (svga). E and F, Localization of Mi-6D4 protein in the subventral glands (svg), dorsal gland ( $\mathrm{dg}$ ), dorsal gland extension (dge), and dorsal gland ampulla (dga). Left panel, fluorescence images of ALEXA-488 and DAPI-stained nuclei appear paired with corresponding DIC overlays on the right panel. $\mathrm{m}$, metacorpus. Bars $=10 \mu \mathrm{m}$. localization in nematode tissues using the BM method. Our results show that all seven antibodies cross reacted with the respective nematode organs or with the cytoskeleton (Figs. 1 to 3 ). Longitudinal sections of preparasitic nematodes showed labeling of the amphids by the Mi-MAP-1 antibody (Fig. 1A and B). Sections allowed good antibody penetration in all amphidial structures, including amphidial glands and the duct that connects the gland to the amphidial pore (Fig. 1A and B). When compared with a whole-mount immunolocalization procedure, Mi-MAP-1 localized mainly in the amphidial pores, suggesting difficulties with antibody penetration into the respective amphidial glands (Fig. 1C and D; 33,37).

It has been shown previously that both Mi-CBM2-bearing and Mi-PEL3 antibodies localized to the subventral glands of
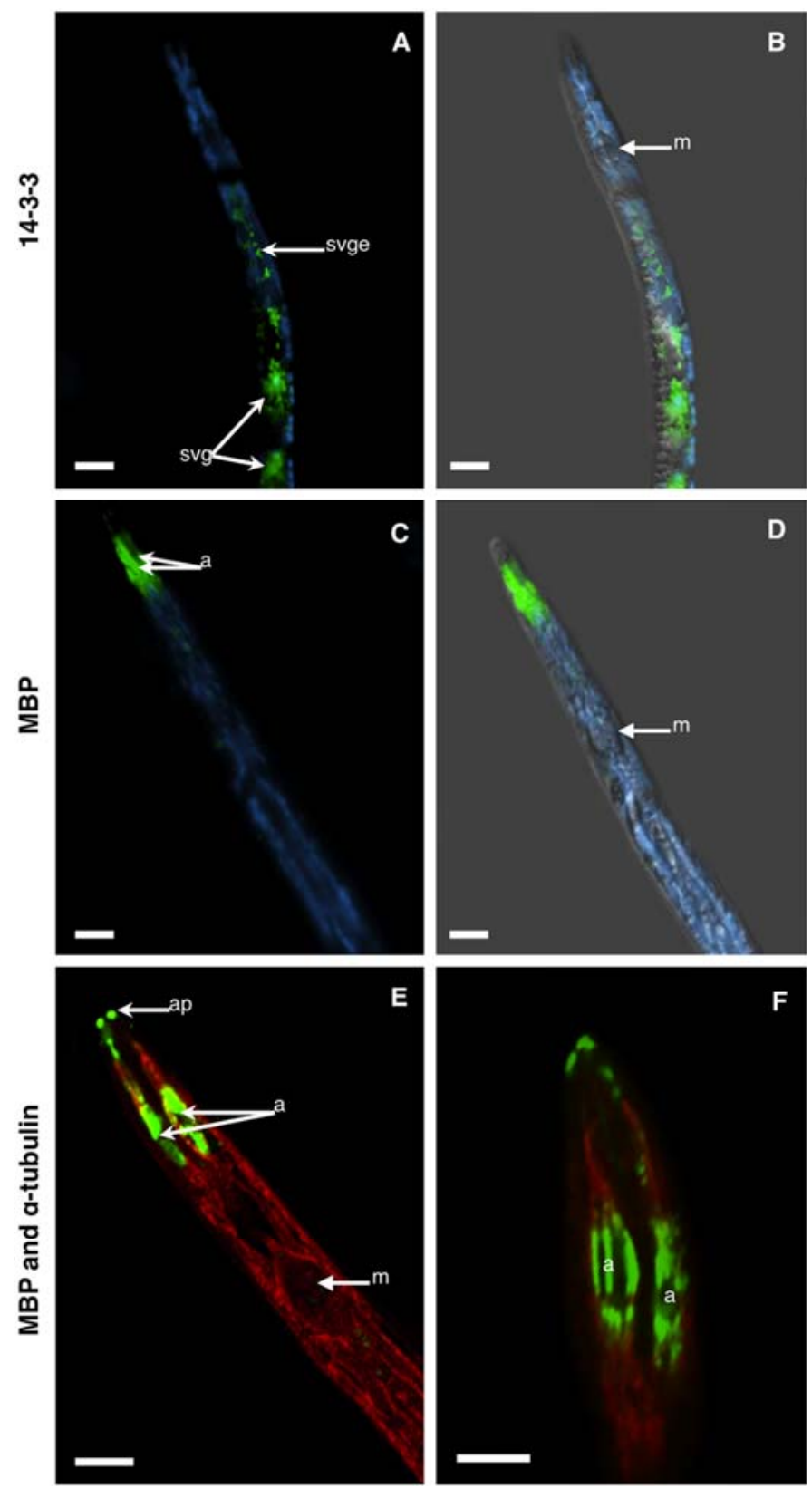

Fig. 3. Immunolocalization of nematode proteins in methacrylate sections of preparasitic juveniles of Meloidogyne incognita. A and B, Localization of 143-3 proteins in the subventral glands (svg). $\mathbf{C}$ and $\mathbf{D}$, Localization of microtubule binding proteins (MBP) in the amphids (a). E and F, Doubleimmunolocalization of MBP in the amphids, and $\alpha$-tubulins within the nematode body cells. A and C, Fluorescence images of ALEXA-488 and ALEXA594-stained nuclei appear paired with corresponding DIC overlays (B and D) on the right panel. $\mathrm{m}$, metacorpus. Bars $=10 \mu \mathrm{m}$. 
preparasitic $\mathbf{J} 2$, using a whole-mount methodology (37). Here, we could show for both proteins, the labeling of the two nematode subventral glands, their gland extensions and corresponding gland ampullae, localized posteriorly to the nematode metacorpus (Fig. $2 \mathrm{~A}$ to $\mathrm{D})$. Whereas for the Mi-6D4 protein strong labeling was detected in the dorsal gland and respective gland extension that ends up in the dorsal ampulla, terminating near the base of the stylet (Fig. 2E and F). In addition, and as shown before (19), we could also observe a weak reaction of this antibody against the nematode subventral glands (Fig. 2E and F).

The localization of the 14-3-3 was observed in the subventral glands (Fig. 3A and B), as previously suggested by transcript localization with in situ hybridization (21). This localization was further confirmed by electron microscope observations where the 14-3-3 protein was seen within the secretory granules of the subventral glands of preparasitic J2.

The anti- $\gamma$-tubulin of Arabidopsis cross reacted with an unknown microtubule binding protein (MBP) of $M$. incognita localized to the amphidial glands (Fig. 3C and D). This result was confirmed by electron microscopy where this protein was apparently abundant within the amphids associated with microtubules (Supplementary Figure 3). Double immunolocalization experiments localized microtubules throughout the nematode body using anti- $\alpha$-tubulins, simultaneously with the anti- $\gamma$-tubulin that localized an MBP within the nematode amphidial glands (Fig. 3E and F).
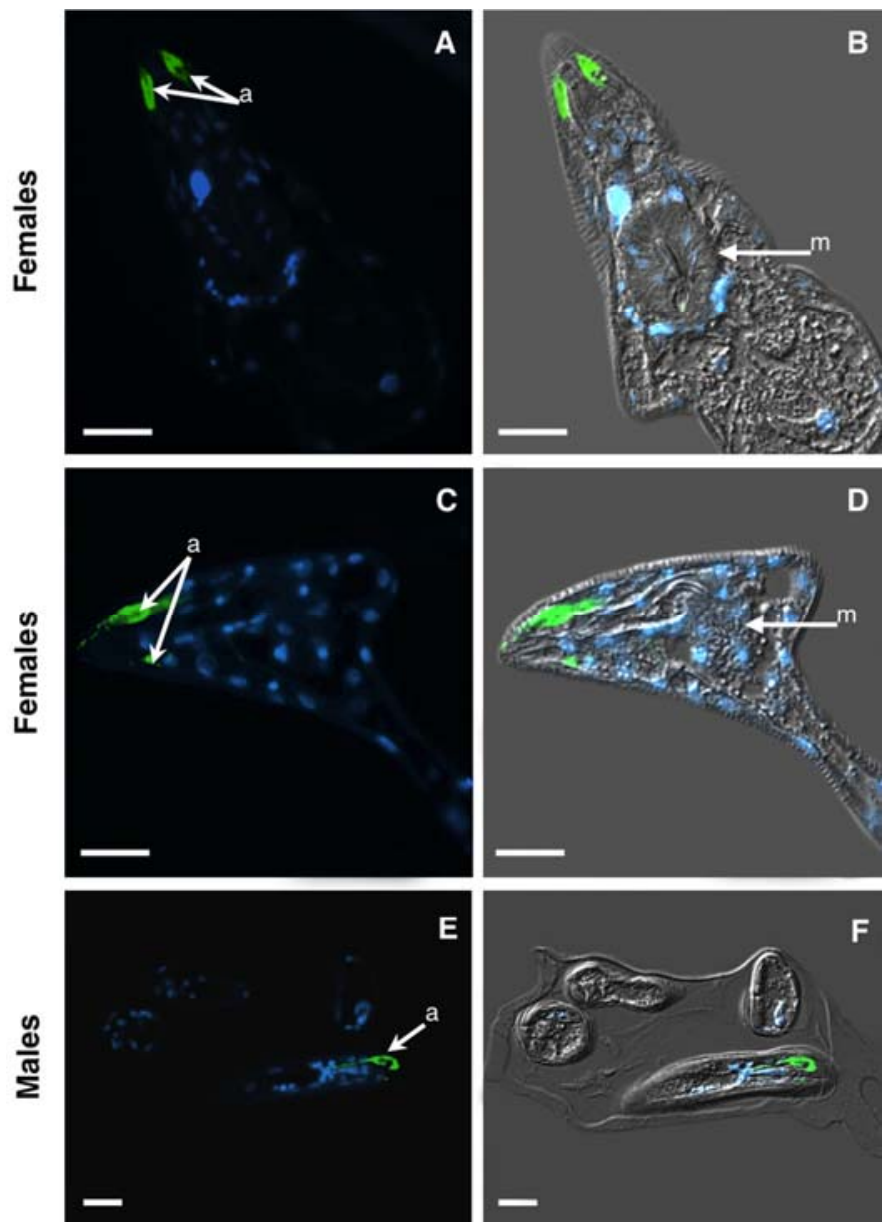

Fig. 4. Immunolocalization of Mi-MAP-1 protein in methacrylate sections of Meloidogyne incognita sedentary stages. A to D, Localization of Mi-MAP-1 protein in the amphids (a) of sedentary females. $\mathbf{E}$ and $\mathbf{F}$, Localization of Mi-MAP-1 protein in the amphids (a) of a coiled male in the J4 cuticle. Left panel, fluorescence images of Alexa-488 and DAPI-stained nuclei appear paired with corresponding DIC overlays on the right panel. $\mathrm{m}$, metacorpus. Bars $=10 \mu \mathrm{m}$.
Control experiments using respective pre-immune sera in place of the primary antibody (Supplementary Figures 4 and 5) or in the absence of primary antibody, revealed no background fluorescence in any nematode tissue.

Immunolocalization of proteins in sedentary nematode stages. One key goal of the current study was to validate the protocol in sedentary parasitic stages extracted from infested roots. Therefore, sections containing a pool of mixed sedentary nematode stages extracted from infected tomato roots were used for the localization of four antibodies, namely Mi-CBM2-bearing proteins, Mi-MAP-1, Mi-PEL3, and Mi-6D4. As for preparasitic stages, Mi-MAP-1 was consistently localized in the amphids of sedentary stages (Fig. 4A to D), including male amphids coiled in the J4 cuticle (Fig. 4E and F). Few studies have shown protein localization within amphids of $M$. incognita $(6,7,26,35)$. Although
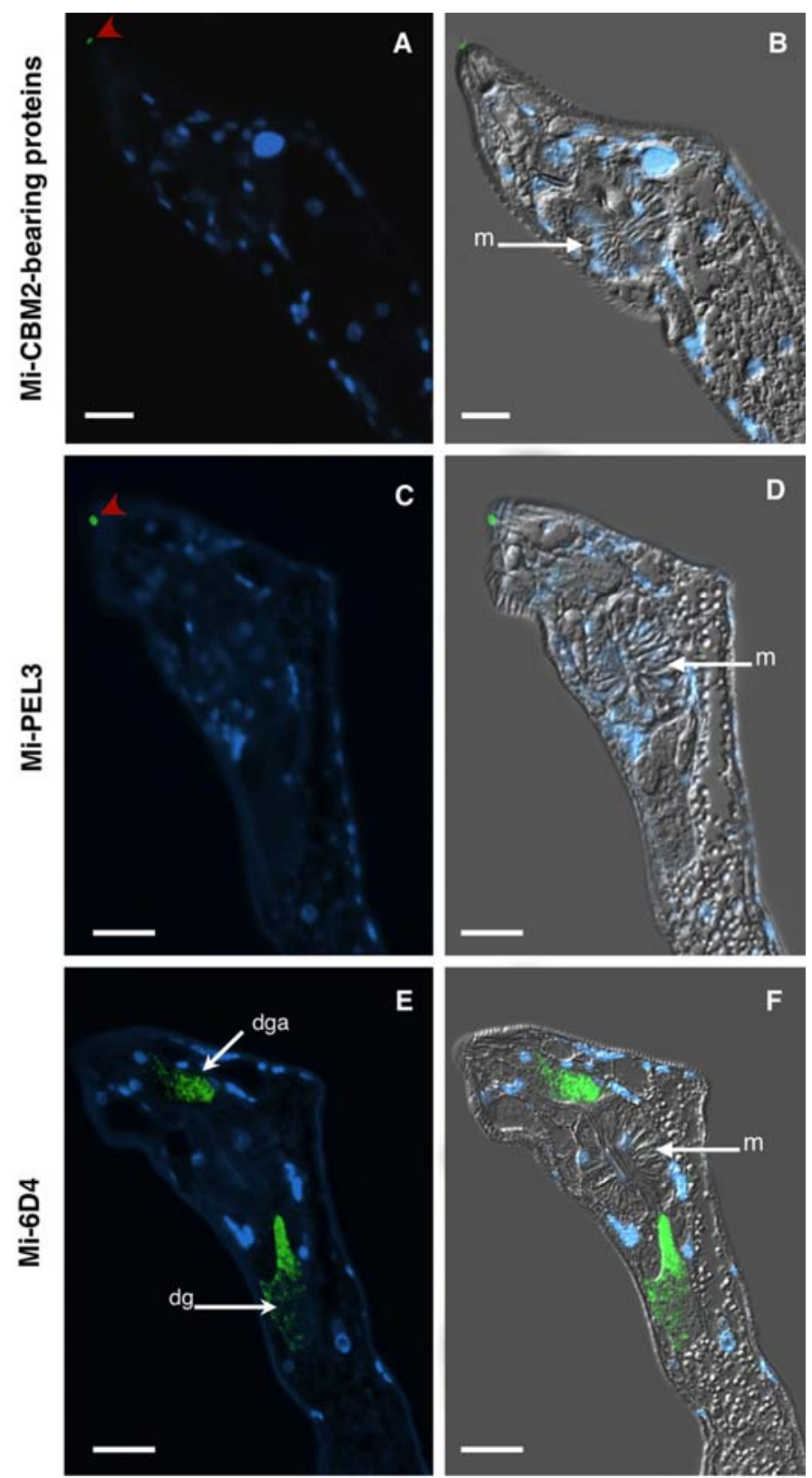

Fig. 5. Immunolocalization of nematode proteins in methacrylate sections of Meloidogyne incognita sedentary stages. A and B, Localization of Mi-CBM2bearing proteins at the oral aperture (arrow). C and D, Localization of MiPEL3 protein at the oral aperture (arrow). E and F, Localization of Mi-6D4 protein in the dorsal gland $(\mathrm{dg})$ and dorsal gland ampulla. Left panel, fluorescence images of Alexa-488 and DAPI-stained nuclei appear paired with corresponding DIC overlays on the right panel. m, metacorpus. Bars $=10 \mu \mathrm{m}$. 
it has been suggested that the amphids of mature adult RKN females might be nonfunctional (35), other studies have demonstrated labeling of an antigen in developing females (7).

Consistent with RKN development, as second-stage juveniles become sedentary, the subventral glands become reduced and seemingly inactive, while the dorsal gland enlarges and shows increased activity during nematode parasitism, including adult females (4). There is evidence that cell wall-degrading enzymes, produced by the subventral glands, are secreted during migratory juveniles. These proteins are thought to assume a critical role in plant cell wall degradation and softening, as they are mainly expressed in J2s $(13,17,24,31)$. Secretion of these enzymes seems to occur during penetration and migration of RKN within the host roots $(13,37)$. Surprisingly, in some sections of sedentary nematodes extracted from the roots, we still observed fluorescence of both Mi-CBM2-bearing proteins (Fig. 5A and B) and Mi-PEL3 (Fig. 5C and D) at the nematode oral aperture. These data were consistent with our previous results where both Mi-CBM2bearing proteins and Mi-PEL3 antibodies could also be localized at the stylet tip of sedentary second-stage juveniles within the host root, most likely resulting from a residual activity of both subventral glands (37). Alternatively, strong Mi-6D4 accumulation in the dorsal gland and respective gland ampulla (Fig. 5E and F), exemplify a protein present at later stages of RKN development. As well, we validated the localization of the MiCBM2-bearing protein in the vagina of adult females (Fig. 6A and B). Although it has been suggested that these proteins could be expressed by the rectal glands of the adult females (31), our results suggest that no link exists between the rectal glands and these proteins since no signal was detected in sections containing the rectal glands of adult RKN. Thus, it remains to be determined whether the female vagina itself, or some other organ, produced this protein.

Control experiments, using the respective pre-immune serum of the corresponding primary antibodies, as well as the use of only the secondary antibody, revealed virtually no background fluorescence for all nematode tissues (Supplementary Figure 6).

Conclusions. Here we present an adapted BM embedding and immunolocalization protocol that optimally preserves the integrity of nematode organs and tissues for all life cycle stages (preparasitic and sedentary), including gall development. It also allows the accessibility of antibodies for protein localization. Embedded biological material can be stored indefinitely, a large number of serial sections can be analyzed and more than one protein can be simultaneously visualized. The method also allows the use of nuclear or other organelle staining. Consecutive slides used for immunolocalization can also be used for in situ hybridizations (23), offering higher resolution, although with less sensitivity than when performed in thicker paraffin sections. This method will be extremely useful in the near future, when a collec-
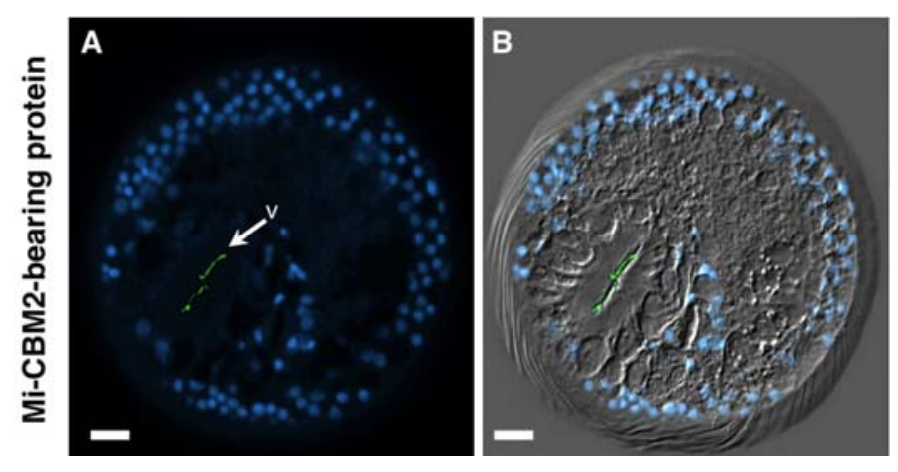

Fig. 6. Immunolocalization of Mi-CBM2-bearing proteins in the vulva of Meloidogyne incognita adult females. A, Fluorescence images of Alexa-488 and DAPI-stained nuclei appear paired with corresponding DIC overlay (B). v, vulva. Bars $=10 \mu \mathrm{m}$. tion of nematode proteins, involved in growth and reproduction and potentially secreted, can be localized before and during parasitism within the nematode as well as in the plant tissue. Thus, in a quite simple manner, a bank of BM blocks, containing samples and sectioned slides, can be generated and systematically screened for nematode protein(s) localization. An additional benefit is to extend this method to the simultaneous localization of plant proteins. This method can be ultimately broadened to the localization of proteins during other interactions between microbes and host plants.

\section{ACKNOWLEDGMENTS}

We thank T. Bleve-Zacheo and M. T. Melillo (Istituto per la Protezione delle Piante, Italy) for the electron microscope IL of the microtubule binding protein, S. Pagnotta (Centre Commun de Microscopie Appliquée, Université de Nice Sophia Antipolis, France) for the 14.3.3 localization, N. Marteu for the production of biological material, and E. Matticola for revising the English language. P. Vieira has been supported by a doctoral scholarship from Fundação para a Ciência e para a Tecnologia from Portugal (SFHR\BD\41339\2007).

\section{LITERATURE CITED}

1. Banora, M. Y., Rodiuc, N., Baldacci-Cresp, F., Smertenko, A., BleveZacheo, T., Mellilo, M. T., Karimi, M., Hilson, P., Evrard, J. L., Favery, B., Engler, J., Abad, P., and de Almeida Engler, J. 2011. Feeding cells induced by phytoparasitic nematodes require $\gamma$-tubulin ring complex for microtubule reorganization. Plos Pathog. 12:e1002343.

2. Baskin, T. I., Busby, C. H., Fowke, L. C., Sammut, M., and Gubler, F. 1992. Improvements in immunostaining samples embedded in methacrylate: Localisation of microtubules and other antigens throughout developing organs in plants of diverse taxa. Planta 187:405-413.

3. Bellafiore, S., Shen, Z., Rosso, M.-N., Abad, P., Shih, P., and Briggs, S. P. 2008. Direct identification of the Meloidogyne incognita secretome reveals proteins with host cell reprogramming potential. Plos Pathog. 4:e1000192

4. Bird, A. F. 1983. Changes in dimensions of the esophageal glands in rootknot nematodes during the onset of parasitism. Int. J. Parasitol. 13:343348 .

5. Coolen, W. A. 1979. Methods for the extraction of Meloidogyne spp. species and other nematodes from roots and soil. Pages 317-329 in: RootKnot Nematodes (Meloidogyne Species) Systematics, Biology and Control. F. Lamberti and C. E. Taylor, eds. Academic Press, London \& New York.

6. Curtis, R. H. C. 1996. Identification and in situ and in vitro characterization of secreted proteins produced by plant-parasitic nematodes. Parasitology 113:589-597.

7. Davis, E. L., Aron, L. M., Pratt, L. H., and Hussey, R. S. 1992. Novel immunization procedures used to develop monoclonal antibodies that bind to specific structures in Meloidogyne spp. Phytopathology 82:12441250.

8. Davis, E. L., Hussey, R. S., Baum, T. J., Bakker, J., Schots, A., Rosso, M.N., and Abad, P. 2000. Nematode parasitism genes. Annu. Rev. Phytopathol. 38:365-396.

9. De Almeida Engler, J., Poucke K. V., Karimi, M., De Groodt, R., Gheysen, G., Engler, G., and Gheysen, G. 2004. Dynamic cytoskeleton rearrangements in giant cells and syncytia of nematode-infected roots. Plant J. 38:12-26.

10. De Almeida Engler, J., Van Montagu, M., and Engler, G. 1994. Hybridization in situ of whole-mount messenger RNA in plants. Plant Mol. Biol. Rep. 12:321-331.

11. De Almeida Engler, J., Van Montagu, M., and Engler, G. 1998. Whole-Mount in situ hybridization in plants. Pages 373-384 in: Arabidopsis Protocols. Methods in Molecular Biology. J. M. Martínez-Zapater and J. Salinas, eds. Humana Press, Totowa, NJ.

12. De Boer, J. M., Yan, Y., Smant, G., Davis, E. L., and Baum, T. J. 1998. In situ hybridization to messenger RNA in Heterodera glycines. J. Nematol. 30:309-312.

13. Doyle, E. A., and Lambert, K. N. 2002. Cloning and characterization of an esophageal-gland-specific pectate lyase from the root-knot nematode Meloidogyne javanica. Mol. Plant-Microbe Interact. 15:549-556.

14. Erben, R. G. 1997. Embedding of bone samples in methylmethacrylate: An improved method suitable for bone histomorphometry, histochemistry, and immunohistochemistry. J. Histochem. Cytochem. 45:307-313.

15. Gubler, F. 1989. Immunofluorescence localisation of microtubules in 
plant root tips embedded in butyl-methyl methacrylate. Cell Biol. Int. Rep. 13:137-145.

16. Harris, P. J., and Rubin, B. P. 1987. Transition from mitosis to interphase in sea urchin first division: Immunofluorescence studies of tubulin distribution in methacrylate sections. J. Histochem. Cytochem. 35:343-349.

17. Huang, G., Dong, R., Allen, R., Davis, E., Baum, T., and Hussey, R. S. 2005. Developmental expression and molecular analysis of two Meloidogyne incognita pectate lyase genes. Int. J. Parasitol. 35:685-692.

18. Huang, G., Gao, B., Maeir, T., Allen, R., Davis, E. L., Baum, T. J., and Hussey, R. S. 2003. A profile of putative parasitism genes expressed in the esophageal gland cells of the root-knot nematode Meloidogyne incognita. Mol. Plant-Microbe Interact. 16:376-381.

19. Hussey, R. S., Paguio, O. R., and Seabury, F. 1990. Localization and purification of a secretory protein form the esophageal glands of Meloidogyne incognita with a monoclonal antibody. Phytopathology 80:709-714.

20. Jaouannet, M., Perfus-Barbeoch, L., Deleury, E., Magliano, M., Engler, G., Vieira, P., Danchin, G. J., Da Rocha, M., Coquillard, P., Abad, P., and Rosso, M.-N. 2012. A root-knot nematode-secreted protein is injected into giant cells and targeted to the nuclei. New Phytol. 194:924-931.

21. Jaubert, S., Laffaire, J. B., Ledger, T. N., Escoubas, P., Amri, E. Z., Abad, P., and Rosso, M. N. 2004. Comparative analysis of two 14-3-3 homologues and their expression pattern in the root-knot nematode Meloidogyne incognita. Int. J. Parasitol. 36:873-880.

22. Jaubert, S., Milac, A. L., Petrescu, J., de Almeida Engler, J., Abad, P., and Rosso, M.-N. 2005. In planta secretion of a calreticulin by migratory and sedentary stages of root-knot nematode. Mol. Plant-Microbe Interact. 18:1277-1284.

23. Kronenberger, J., Desprez, T., Höfte, H., Caboche, M., and Traas, J. 1993. A methacrylate embedding procedure developed for immunolocalization on plant tissues is also compatible with in situ hybridization. Cell Biol. Int. 17:1013-1021.

24. Ledger, T. N., Jaubert, S., Bosselut, N., Abad, P., and Rosso, M.-N. 2006. Characterization of a new $\beta$-1,4-endoglucanase gene from the root-knot nematode Meloidogyne incognita and evolutionary scheme for phytonematode family 5 glycosyl hydrolases. Gene 382:121-128.

25. Leone, A., Melillo, M. T., and Bleve-Zacheo, T. 2001. Lipoxygenase in pea roots subjected to biotic stress. Plant Sci. 161:703-717.

26. Lima, L. M., Grossi-de-Sá, M. F., Pereira, R. A., and Curtis, R. H. C. 2005. Immunolocalisation of secreted-excreted products of Meloidogyne spp. using polyclonal and monoclonal antibodies. Fitopatol. Bras. 30:629633.

27. Neveu, C., Jaubert, S., Abad, P., and Castagnone-Sereno, P. 2003. A set of genes differentially expressed between avirulent and virulent Meloido- gyne incognita near-isogenic lines encode secreted proteins. Mol. PlantMicrobe Interact. 16:1077-1084.

28. Niebel, A., de Almeida Engler, J., Tiré, C., Engler, G., Van Montagu, M., and Gheysen, G. 1993. Induction patterns of an extensin gene in tobacco upon nematode infection. Plant Cell 5:1697-1710.

29. Pastuglia, M., Azimzadeh, J., Goussot, M., Camilleri, C., Belcram, K., Evrard, J. L., Schmit, A. C., Guerche P., and Bouchez, D. 2006. $\gamma$-Tubulin is essential for microtubule organization and development in Arabidopsis. Plant Cell 18:1412-1425.

30. Rosso, M., Hussey, R., Davis, E. L., Smant, G., Baum, T., Abad, P., and Mitchum, M. G. 2011. Nematode effector proteins: Targets and functions in plant parasitism. Pages 327-354 in: Effectors in Plant-Microbe Interactions. F. Martin and S. Kamoun, eds. John Wiley \& Sons, Inc., New York.

31. Rosso, M.-N., Favery, B., Piotte, C., Arthaud, L., De Boer, J. M., Hussey, R. S., Bakker, J., Baum, T. J., and Abad, P. 1999. Isolation of a cDNA encoding a beta-1,4-endoglucanase in the root-knot nematode Meloidogyne incognita and expression analysis during plant parasitism. Mol. Plant-Microbe Interact. 12:585-591.

32. Ruzin, S. E. 1999. Butyl/methyl methacrylate embedding. Page 4 in: Plant Microtechnique and Microscopy. S. E. Ruzin, ed. Oxford University Press, New York.

33. Semblat, J. P., Rosso, M.-N., Hussey, R. S., Abad, P., and CastagnoneSereno, P. 2001. Molecular cloning of a cDNA encoding an amphidsecreted putative avirulence protein from the root-knot nematode Meloidogyne incognita. Mol. Plant-Microbe Interact. 14:72-79.

34. Sims, P. A., and Hardin, J. D. 2007. Fluorescence-integrated transmission electron microscopy images: Integrating fluorescence microscopy with transmission electron microscopy. Methods Mol. Biol. 369:291-308.

35. Stewart, G. R., Perry, R. N., and Wright, D. J. 1993. Studies on the amphid specific glycoprotein gp32 in different life-cycle stages of Meloidogyne species. Parasitology 107:573-578.

36. Torgersen, J. S., Takle, H., and Andersen, O. 2009. Localization of mRNAs and proteins in methyl methacrylate-embedded tissues. J. Histochem. Cytochem. 57:825-830.

37. Vieira, P., Danchin, E. G. J., Neveu, C., Crozat, C., Juabert, S., Hussey, R. S., Engler, G., Abad, P., de Almeida-Engler, J., Castagnone-Sereno, P., and Rosso, M.-N. 2011. The plant apoplasm is an important recipient compartment for nematode secreted proteins. J. Exp. Bot. 62:1241-1253.

38. Warren, K. C., Coyne, K. J., Waite, J. H., and Cary, S. C. 1998. Use of methacrylate de-embedding protocols for in situ hybridization on semithin plastic sections with multiple detection strategies. J. Histochem. Cytochem. 46:149-155. 